\title{
A NOVA DIREITA CRISTÃ: ALIANÇAS, ESTRATÉGIAS E TRANSFIGURAÇÃO DO DISCURSO RELIGIOSO EM TORNO DO PROJETO DE CURA GAY
}

\author{
Graziela Ferreira QUINTÃO*
}

\begin{abstract}
RESUMO: O alargamento dos direitos LGBT, assim como ações que promovem a visibilidade e aceitação desses grupos sociais vêm provocando reações conservadoras de diferentes vertentes da fé cristã, sobretudo de evangélicos pentecostais. O presente artigo busca examinar a atuação de parlamentares da Frente Parlamentar Evangélica do Congresso Nacional, na tramitação do projeto de decreto constitucional (PDC 234/2011), proposto pelo deputado federal João Campos (PSDB-GO), propondo uma análise, com foco nas alianças, estratégias e discursos construídos na arena política. Como recurso metodológico faz-se referência aos discursos e debates proferidos nas audiências públicas derivadas do referido projeto de decreto constitucional. Como fonte de consulta, utilizam-se as notas taquigráficas referentes às audiências públicas e reuniões ordinárias das Comissões de Direitos Humanos e Minorias (CDHM) e de Seguridade Social e Família (CSSF) da Câmara Federal, complementadas por vídeos e matérias de veículos midiáticos, condizentes às mesmas.
\end{abstract}

PALAVRAS-CHAVE: Ativismo político-religioso. Conservadorismo religioso. PDC 234/2011. Frente Parlamentar Evangélica. Movimento LGBT.

\section{Introdução}

Os elementos precursores de uma hostilidade contra homossexuais emanam da tradição judaico-cristã; para o pensamento pagão, a sexualidade entre

\footnotetext{
UFF - Universidade Federal Fluminense. Escola de Serviço Social. Programa de Estudos Pós-Graduados em Política Social. Niterói - RJ - Brasil. 24210-201 - grazielaquintao@id.uff.br.
} 
pessoas do mesmo sexo era considerada um elemento constitutivo, até mesmo indispensável, da vida do indivíduo, sobretudo masculino. O cristianismo, por sua vez, ao acentuar a Lei Judaica, começou a situar os homossexuais, não só fora da Salvação, mas também, e sobretudo, à margem da Natureza. A homossexualidade, sendo uma sexualidade não reprodutora (forma paradigmática do ato estéril por essência) constituirá, daí em diante, a configuração mais acabada do pecado contra a natureza (BORRILO, 2013). De acordo com Natividade (2009), argumentos naturalistas são utilizados tanto na caracterização de um uso sadio e apropriado do corpo, como na proposta de manutenção dos papéis de gênero tradicionais e complementares. Borrilo (2013) assinala que o sistema de dominação masculina do tipo patriarcal consolida-se com a tradição judaico-cristã, sendo introduzida uma nova dicotomia heterossexualidade/homossexualidade. O cristianismo transformará a heterossexualidade no único comportamento suscetível de ser qualificado como natural e, por conseguinte, como normal, inaugurando assim, no Ocidente, uma época de homofobia, ainda não praticada por outra civilização.

No contexto brasileiro, a homofobia religiosa evangélica vem se destacando nas últimas décadas como um fenômeno com implicações importantes na obstrução da produção de políticas para a população Lésbicas, Gays, Bissexuais, Travestis (LGBT).

A partir de 2004, um conjunto de iniciativas (ações e programas) governamentais nacionais começava a assegurar a promoção de cidadania para a população LGBT, evidenciando, concomitantemente, a necessidade de implementação de políticas públicas no combate ao preconceito, à discriminação e à exclusão que atingem essa população. O alargamento dos direitos LGBT, assim como ações que promovem a visibilidade e aceitação desses grupos sociais vêm provocando reações conservadoras de diferentes vertentes da fé cristã, sobretudo de evangélicos pentecostais. Utilizando a retórica da liberdade de expressão, esses segmentos religiosos desqualificam e combatem a diversidade sexual, adentrando a arena política através de seus representantes no Congresso Nacional, que se articulam compondo frentes parlamentares e interferindo na agenda do movimento LGBT no sentido de conseguir o veto de leis e políticas que contrariam preceitos morais da sua comunidade religiosa.

O presente artigo busca examinar a atuação de parlamentares da Frente Parlamentar Evangélica do Congresso Nacional, na tramitação do projeto de decreto constitucional (PDC 234/2011), apresentado pelo deputado federal por Goiás, João Campos, do Partido da Social Democracia Brasileira (PSDB-GO). Propõe também, uma análise, com foco nas alianças, estratégias e discursos construídos na arena política. Como recurso metodológico faz-se referência aos discursos e debates proferidos nas audiências públicas derivadas do referido projeto de decreto 


\section{A nova direita cristã: alianças, estratégias e transfiguraçâo do discurso religioso em torno do projeto de cura gay}

constitucional. Como fonte de consulta, utiliza-se as notas taquigráficas referentes às audiências públicas e reuniões ordinárias das Comissões de Direitos Humanos e Minorias (CDHM) e de Seguridade Social e Família (CSSF) da Câmara Federal, complementadas por vídeos e matérias de veículos midiáticos, condizentes às mesmas.

\section{Movimento pentecostal: surgimento, características e expansão no Brasil}

O pentecostalismo foi formado no início do século XX nos EUA. Os personagens e lugares usualmente apresentados como marcos inaugurais ou referências históricas do moderno movimento pentecostal são: Charles Fox Parham (1901), em Topeka (Kansas), que conduziu experiências místicas na Bettel Bible College; e William Joseph Seymor, um negro filho de ex-escravos, que a partir da influência de Parham, tornou-se líder de uma igreja na Azuza Street, em Los Angeles/Califórnia, em 1906, com grande disseminação entre os pobres, imigrantes e deserdados (CAMPOS, 2005). Posteriormente, se expandiu para a Europa e vários países em desenvolvimento no sul do Pacífico, da África, do leste e sudeste da Ásia, e, sobretudo na América Latina, onde o Brasil se destaca (MARIANO, 2004; CAMPOS, 2005).

O fenômeno do pentecostalismo deve ser visto no plural, à luz da multiplicidade de culturas que condicionaram a sua origem e desenvolvimento em todo o mundo (CAMPOS, 2005). No Brasil, essa denominação religiosa assimilou traços das culturas indígena, católica e religiões mediúnicas afro-kardecistas.

A história e as características do pentecostalismo no Brasil têm sido abordadas de formas diferenciadas. Freston (1993) e outros autores (MARIANO, 2004; SILVA, 2009) têm usado a periodização das três ondas de implantação das igrejas, em distinções teológicas e comportamentais. A primeira onda constitui o pentecostalismo clássico, e abrange as igrejas pioneiras: Congregação Cristã (1910) e Assembleia de Deus (1911), fundadas por missionários europeus, que converteram-se ao pentecostalismo nos Estados Unidos, de onde vieram para evangelizar o Brasil. Ambas as igrejas caracterizaram-se pelo anticatolicismo, por radical sectarismo e ascetismo de rejeição do mundo. No plano teológico, enfatizaram o dom de falar em línguas (glossolalia), seguindo a ênfase doutrinária primitiva dessa religião, e têm o campo para si durante quarenta anos, uma vez que suas rivais são inexpressivas. A segunda está entre 1950 e início de 1960 e, diferente da primeira onda, não enfatiza a glossolalia ou os dons do Espírito Santo, mas sim a cura divina. Na década de 1950, em São Paulo, criaram a Cruzada 
Nacional de Evangelização, por meio da qual, iniciaram o evangelismo focado na pregação da cura divina, atraindo multidões às concentrações evangelísticas na capital paulista, o que acelerou a expansão do pentecostalismo brasileiro. Em 1953, fundaram a Igreja Evangélica Quadrangular.

A terceira onda, designada de neopentecostal, inicia-se na segunda metade da década de 1970. As igrejas: Universal do Reino de Deus em 1977 no Rio de Janeiro (RJ), Internacional da Graça de Deus em 1980 (RJ), Comunidade Evangélica Sara Nossa Terra, 1976 em Goiás (GO) e Renascer em Cristo (1986) em São Paulo (SP), fundadas por pastores brasileiros, constituem as principais. Há um rompimento (ou abrandamento) do ascetismo e sectarismo; igrejas organizadas em contornos empresariais; ênfase na teologia da prosperidade; liberalização no que diz respeito aos usos e costumes; utilização da mídia para o trabalho de proselitismo em massa e de propagandas religiosas, e crença proeminente na guerra espiritual contra Satanás, os demônios e seus representantes na Terra, centralizando a batalha contra as outras denominações religiosas, sobretudo, as afro-brasileiras e o kardecismo.

Freston (1993) defende que o estudo sociológico da religião requer a compreensão das grandes igrejas pentecostais enquanto instituições em evolução dinâmica, e não organizações estáticas que incham numericamente. Estão em constante adaptação e as mudanças são frequentemente objeto de lutas, a partir das quais o campo pentecostal se fragmenta, a relação com a sociedade se dinamiza e outros grandes grupos surgem. "Ademais, o pentecostalismo possui grande variedade de formas, e cada nova espécie vai enterrando mais alguns mitos a respeito de o pentecostalismo" (FRESTON, 1993, p.64).

O neopentecostalismo é a vertente pentecostal que mais cresce no Brasil. De acordo com o Censo 2010 (IBGE, 2010), os evangélicos passaram dos 15,4\% em 2000 para $22,2 \%$ em 2010. Isto representa um aumento de cerca de 16 milhões de pessoas (de 26,2 milhões para 42,3 milhões). Desse total, 60,0\% era de origem pentecostal. Conforme Mariano (2004, p. 124), "sem perder necessariamente sua distintividade religiosa, as igrejas neopentecostais revelam-se, entre as pentecostais, as mais inclinadas a acomodarem-se à sociedade abrangente e a seus valores, interesses e práticas." A Igreja Universal se destaca entre as neopentecostais pelo seu acelerado crescimento institucional, constituindo-se em um verdadeiro império, que se justifica, entre outros fatores, pela acentuada capacidade de arrecadar recursos, que "se deve em grande parte à sua agressividade, insistência e incomparável habilidade persuasiva nessa matéria” (MARIANO, 2004, p. 129).

Ao longo desse processo de expansão, essas denominações evangélicas vêm exercendo poder de influência para além do campo religioso, adentrando arenas de disputas políticas através dos parlamentares que as representam, e se articulando a fim de influenciar a agenda de políticas públicas e a proposição de leis. 


\section{A Assembleia Nacional Constituinte e a irrupção pentecostal na política}

A partir de 1986, a atuação política dos evangélicos se transforma, há uma irrupção pentecostal que rompe com dito tradicional de que crente não se mete em política (FRESTON, 1993; PIERUCCI, 1989). Assim como outros segmentos organizados da sociedade, a Assembleia de Deus se mobilizou de forma estratégica para ter representatividade no Congresso Nacional. Em reunião da Convenção Geral das Assembleias de Deus no Brasil realizada em Anápolis, estado de Goiás (GO), em janeiro de 1985, políticos evangélicos de outras denominações convidados a falar, apelaram para que a Assembleia de Deus se envolvesse no Congresso Constituinte. Meses depois, a Convenção Geral convocou os presidentes de convenções estaduais para um encontro em Brasília, após o qual a Assembleia de Deus de quatorze estados apresentou candidatos oficiais de seus próprios quadros, e em quatro estados, apoiou outros candidatos pentecostais. A Assembleia de Deus conseguiu eleger 13 deputados e um suplente assumiu o mandato após o Congresso Constituinte. O que representou a esmagadora maioria entre os pentecostais eleitos (18), na bancada formada por 34 deputados de origem evangélica (FRESTON, 1993).

Conforme Pierucci (1989, p.105), a bancada de 34 deputados evangélicos não era política e ideologicamente homogênea, e tampouco suas bases de voto: "Além de visíveis e mensuráveis, apareciam como inesperadamente vocais na manifestação e na defesa de suas convicções religiosas e de seus pontos de vista sobre a sociedade", o que resultou em reforço à pressão conservadora sobre a nova constituição. Este ativismo político-religioso de caráter conservador-tradicionalista-restauracionista dos valores morais sexuais tradicionais, representou para as coalizões de direita um novo e fenomenal aporte de recursos culturais e retóricos, constituindo assim, tal como nos Estados Unidos da América (EUA), dadas suas semelhanças e parentesco com o New Christian Right estadunidense, uma ala nada desprezível da chamada nova direita.

Os discursos e práticas derivados das alianças à direita no Congresso Constituinte se confirmam em votações específicas sobre temas morais e comportamentais, tais como a homossexualidade. Após a exposição do ativista do Movimento Homossexual Brasileiro, João Antônio Mascarenhas ${ }^{1}$ à Subcomissão dos Direitos e Garantias Individuais, na qual referiu-se à necessidade de incluir a proibição de discriminação por orientação sexual na Revisão Constitucional, a maior oposição veio da bancada evangélica, tendo o deputado de Rondônia, José

\footnotetext{
1 Era advogado e um dos fundadores, em 1978, do jornal Lampião da Esquina, primeira publicação destinada a promover a discussão política da homossexualidade no país, e do grupo Triângulo Rosa.
} 
Viana do Partido do Movimento Democrático Brasileiro (PMDB-RO), contestado a evidência científica de que homossexualidade não é doença, e também utilizado argumentos derivados de interpretações teológicas e exegeses bíblicas particulares, conforme o seguinte trecho de seu pronunciamento: "Apesar de o Conselho Federal de Medicina afirmar que não é doença, eu acredito que o homossexualismo seja doença. [...] A Bíblia Sagrada, que é o livro dos livros e o livro por excelência, condena radicalmente esse ato" (CÂMARA DOS DEPUTADOS, 1993, n.p.).

O termo orientação sexual foi aceito pela subcomissão, mas excluído pela Comissão de Sistematização, apesar de intensa mobilização e dos esforços dos seus defensores - como o deputado José Genoíno do Partido dos Trabalhadores de São Paulo (PT-SP), que argumentou que a Constituinte propunha a proteção à diversidade e à pluralidade religiosa - o termo foi definitivamente rejeitado pelo Plenário, em 28 de janeiro de 1988. A votação foi 130 a favor, 317 contra, com 14 abstenções e 98 ausentes (HOWES, 2003).

\section{A Formação da Frente Parlamentar Evangélica e os impactos para o movimento LGBT}

Em 2003, foi criada a Frente Parlamentar Evangélica (FPE) do Congresso Nacional, com o objetivo de congregar, por meio de cultos semanais, os parlamentares evangélicos. Através desses cultos, poderia ser engendrada uma mobilização estratégica em torno de bandeiras de luta da FPE quanto à promoção e conversão evangélica no âmbito do legislativo (DUARTE, 2012).

Como ocorre em outras frentes parlamentares, o pluripartidarismo é uma estratégia de atuação adotada pelos dirigentes da FPE que abarca tendências ideológicas afins para defender demandas conjunturais. Constitui-se em um modo de atender reivindicações de determinados segmentos, rompendo as barreiras das estruturas dos partidos políticos. A FPE defende os interesses da comunidade evangélica, fazendo oposição à aprovação de projetos que ferem os preceitos bíblicos, o que significa que a oficialização do homossexualismo deveria ser combatida e, portanto, não receber o apoio sob a forma da lei, por ser nociva à sociedade, à moral e aos bons costumes.

Reações religiosas que desqualificam a diversidade sexual são insufladas por sujeitos que percebem a expansão dos direitos dos homossexuais e a visibilidade e aceitação desta parcela da população como ameaçadora de seus valores e da própria ordem social" (NATIVIDADE \& LOPES, 2009, p. 79). 


\section{A nova direita cristã: alianças, estratégias e transfiguração do discurso religioso em torno do projeto de cura gay}

Pressões exercidas por parlamentares da FPE culminaram no cancelamento do programa Escola Sem Homofobia, que ficou conhecido como kit gay. O programa foi alvo da intensa mobilização dos setores conservadores, dentre eles, parlamentares da FPE, a partir da desqualificação do conteúdo e qualidade de seu material, assim como o público a que se destinava, aproveitando de uma situação política específica pelos seus adversários.

\section{a. A eleição de Marco Feliciano para a presidência da CDHM da Câmara Federal}

A eleição do deputado (e pastor evangélico) Marco Feliciano, do Partido Social Cristão (PSC-SP), para a presidência da Comissão de Direitos Humanos e Minorias da Câmara dos Deputados (CDHM) gerou uma onda de manifestações contrárias em redes sociais, campanhas e passeatas de grupos organizados e ativistas dos movimentos LGBT, em decorrência do fato de ter o deputado Marco Feliciano expressado opiniões consideradas racistas e homofóbicas ${ }^{2}$ - além do mesmo não ter um histórico de atuação na temática dos direitos humanos. Líderes evangélicos o apoiaram e o pastor evangélico Silas Malafaia (conhecido por suas declarações contrárias à homossexualidade) escreveu em uma rede social que eles não pautavam suas ações pelo que a mídia ou grupos de pressão do ativismo gay queriam. Para ele o PSC não podia dar moleza. Assim, o deputado Marco Feliciano foi eleito presidente da CDHM, em março de 2013. Houve manifestações e atos de protestos nas ruas, assim como nas primeiras sessões da Comissão presididas pelo mesmo, que reagiu, aprovando um requerimento para restringir o acesso do público às reuniões do colegiado (FOLHA DE SÃO PAULO, 2013, n.p.).

A gestão do deputado Marco Feliciano na CDHM foi marcada pela aprovação de propostas de teor anti-homossexual. A primeira ação de enfrentamento pelo deputado foi a votação do projeto conhecido como cura gay, que pretendia derrubar trechos de uma resolução do Conselho Federal de Psicologia (CFP), que estabelece normas para os psicólogos em relação à questão da orientação sexual, vedando a atuação dos mesmos em eventos e serviços que proponham tratamento e cura da homossexualidade. Foi aprovada ainda, a convocação de plebiscito para consultar a população sobre a união entre pessoas do mesmo sexo e a suspensão da resolução do Conselho Nacional de Justiça (CNJ) que obriga cartórios a validar casamentos

2 O deputado Marco Feliciano havia postado numa rede social, que "africanos descendem de ancestral amaldiçoado por Noé. Isso é fato." E também, que "a podridão dos sentimentos homoafetivos leva ao ódio, ao crime, à rejeição." Além de ter associado a Aids a uma doença gay (NATIVIDADE \& LOPES, 2009). 
de homossexuais. Embora o projeto tenha sido aprovado no colegiado, líderes da Câmara dos Deputados levaram a proposta a plenário, que foi rejeitada pela maioria e arquivada.

Destaca-se ainda, o debate sobre a criminalização da homofobia, decorrente da tramitação do Projeto de Lei da Câmara - PLC 122/2006. Desde o início de sua trajetória, essa proposta enfrenta oposição de setores religiosos conservadores, envolvendo a reprodução de estigmas e a desqualificação dos homossexuais (NATIVIDADE \& LOPES, 2009). Militantes religiosos têm se posicionado na esfera pública, contra a aprovação da criminalização da homofobia, utilizando argumentos que ressaltam o direito à liberdade religiosa. Isto porque o direito dos grupos religiosos de expressar opinião contrária à homossexualidade estaria cerceado, inclusive, no âmbito da atuação em trabalhos pastorais de reversão da homossexualidade. Ao longo da tramitação da PLC 122/2006, evidenciou-se um jogo de forças entre os representantes dos movimentos dos homossexuais e segmentos religiosos.

Em 2011, a senadora Marta Suplicy (PT-SP) ${ }^{3}$ propôs uma nova redação para o projeto, a fim de deixar expresso que não se criminalizaria a manifestação pacífica de pensamento fundada na liberdade de consciência e de crença. Contudo, não houve adesão dos opositores ao projeto, que passou por várias redações. Em 20 de novembro de 2013, a pressão de parlamentares evangélicos retirou o PLC 122/2006 da pauta da CDHM, com o pretexto de se buscar novamente um texto de consenso, até que foi arquivado em janeiro de 2015, e apensado ao projeto de reforma do Código Penal.

\section{Alianças, estratégias e transfiguração do discurso religioso em torno do projeto de cura gay}

Em 02 de junho de 2011, o deputado e presidente da FPE, João Campos (PSDB-GO) protocolou o Projeto de Decreto Legislativo (PDC 234/11), que visava sustar a aplicação do parágrafo único do art. $3^{\circ} \mathrm{e}$ o art. $4^{\circ}$ da Resolução do Conselho Federal de Psicologia ${ }^{\circ} 1$, de 23 de março de 1999, que estabelece normas de atuação para os psicólogos em relação à questão da orientação sexual, conforme segue:

Art. $3^{\circ}$ - os psicólogos não exercerão qualquer ação que favoreça a patologização de comportamentos ou práticas homoeróticas, nem adotarão ação coercitiva

\footnotetext{
3 Faz-se referência à legenda partidária a qual a senadora era filiada. Em 2015, ela saiu do PT para se filiar ao PMDB.
} 


\section{A nova direita cristã: alianças, estratégias e transfiguração do discurso religioso em torno do projeto de cura gay}

tendente a orientar homossexuais para tratamentos não solicitados. Parágrafo único - Os psicólogos não colaborarão com eventos e serviços que proponham tratamento e cura das homossexualidades.

Art. $4^{\circ}$ - Os psicólogos não se pronunciarão, nem participarão de pronunciamentos públicos, nos meios de comunicação de massa, de modo a reforçar os preconceitos sociais existentes em relação aos homossexuais como portadores de qualquer desordem psíquica (CFP, 1999, n.p.)

Em sua justificativa, o deputado João Campos afirma que o CFP, ao restringir o trabalho dos profissionais e o direito da pessoa de receber orientação profissional, por intermédio do questionado ato normativo, extrapolou o seu poder regulamentar, e ao criar e restringir direitos mediante resolução, usurpou a competência do Poder Legislativo, incorrendo em abuso de poder regulamentar, com graves implicações no plano jurídico constitucional, o que implicaria portanto, na sustação do ato normativo, por intermédio de decreto legislativo. O conteúdo deste projeto não é inédito no cenário legislativo brasileiro, conforme registrou o próprio deputado João Campos no texto do PDC, uma vez que na legislatura anterior o deputado Paes de Lira do Partido Trabalhista Cristão (PTC/SP), foi autor de iniciativa semelhante (Projeto de Decreto Legislativo - PDC 1640/2009) a qual foi arquivada no encerramento da mesma.

O CFP considerou um retrocesso a aprovação do projeto pela CDHM, porque feria um direito já consolidado constitucionalmente, e emitiu um parecer, demonstrando como os argumentos do deputado João Campos não se sustentavam, assinalando que ao publicar a Resolução no 001/99 que "estabelece normas de atuação para os psicólogos em relação à questão da Orientação Sexual", o CFP exerceu, simplesmente, sua atribuição de regrar o cotidiano profissional com base na legislação em vigor e no consenso científico a respeito da homossexualidade. Destacamos aqui o posicionamento do CFP, ao apontar a homofobia religiosa intrínseca ao projeto.

O debate efetivo a respeito do PDC 234/2011 se dá em torno desta tradição de exclusão, desrespeito, humilhações e violência que também é reproduzida no Parlamento pelo fundamentalismo religioso e pelas posições homofóbicas seculares. Tudo o mais, os argumentos pseudojurídicos, as preocupações com o poder regulamentador dos conselhos profissionais, a defesa sempre patriótica das prerrogativas legislativas, os discursos inflamados etc., têm a ver com uma única e central questão: a afronta aos direitos civis dos homossexuais e as obrigações que temos de recepcioná-los integralmente, desconstituindo o conjunto de preconceitos herdados e a intolerância que os acompanha como uma sombra (CFP, 2012, n.p.). 


\section{Graziela Ferreira Quintão}

Em junho de 2011, o PDC foi distribuído às comissões de Constituição e Justiça e de Cidadania e de Seguridade Social e Família (CSSF). Na CSSF, foram realizadas três audiências públicas, a partir das quais podemos compreender a dinâmica instaurada entre os defensores e opositores do PDC, assim como suas estratégias.

Em 28 de junho de 2012, a audiência realizada na CSSF foi requerida pelos deputados Roberto de Lucena do Partido Verde (PV-SP) e Marcos Feliciano (PSC-SP). Receberam convites para as palestras, uma Procuradora do Ministério Público do Trabalho, a psicóloga Marisa Lobo e representantes da Organização Mundial de Saúde e do Conselho Federal de Psicologia, contudo, os dois últimos não compareceram. Para essa audiência, não foi convidado nenhum representante do movimento LGBT.

Em sua exposição, a psicóloga Marisa Lobo afirmou sua oposição ao Conselho Federal de Psicologia, considerando-o totalmente arbitrário e utilizou argumentos científicos do campo da psiquiatria, referindo-se a categorias diagnósticas (como a F66.1 do CID 10) para sustentar sua defesa do direito ao tratamento de reversão da orientação sexual, realizado por psicólogos.

O objetivo desta minha exposição é o de tratar da questão da homossexualidade sob o prisma científico e desvinculá-la de quaisquer ideologias. É também de ressaltar o direito que temos à livre escolha, à autonomia e ao acesso de informações não distorcidas, livrando-nos de meias verdades e do pseudoconhecimento científico, os quais têm sido grosseiramente utilizados com finalidade político-ideológicas e totalitária, que têm sido lançados sobre a Nação brasileira nos últimos anos. A generalização sobre a homossexualidade é fictícia e autoritária e suas argumentações são falaciosas. Essa suposta homogeneidade entre os homossexuais, tão propagada por movimentos ditadores, alguns políticos e até pelo próprio Conselho de Psicologia, está longe de se constituir um fato indiscutível. E é precisamente aqui que entra em foco o direito legal e legítimo que possuem as pessoas portadoras de uma sexualidade egodistônica (que destoa do eu), homossexual ou não, de buscarem tratamento psicológico ou psiquiátrico, caso assim bem o desejarem, além do direito que têm e possuem de não compartilharem com a ideologia de tais militâncias (CÂMARA DOS DEPUTADOS, 2012, n.p.). ${ }^{4}$

Durante os debates, o deputado pelo Rio de Janeiro, Jean Wyllys do Partido Socialismo e Liberdade (PSOL-RJ), fez uma série de questionamentos ao PDC e seu

\footnotetext{
4 Todos os discursos referentes às audiências públicas transcritos aqui foram retirados do portal da Câmara dos Deputados: http://www2.camara.leg.br/.
} 


\section{A nova direita cristã: alianças, estratégias e transfiguração do discurso religioso em torno do projeto de cura gay}

autor, sobre a quais grupos de interesse e pressão eles atendem, e também apontou a fragilidade das construções argumentativas na exposição da psicóloga Marisa Lobo, ao indicar que tais construções ocultam argumentos puramente religiosos.

Eu questiono qual é o objetivo de um Deputado que foi delegado da Polícia Federal, por isso está muito mais ligado a esse universo, ao propor um projeto de decreto legislativo que susta pontos de uma resolução do Conselho Federal de Psicologia. Que interesse pode ter esse Parlamentar em se meter nessa história, a não ser que levemos em conta que esse Parlamentar também é evangélico e está na verdade respondendo a pressões de pessoas das suas relações e dos seus interesses? Eu confesso que fiquei constrangido com a fala da única pessoa que se manifestou a esse respeito, a psicóloga Marisa Lobo. Fiquei constrangido com a falta de sustentação teórica, de aprofundamento teórico, da sua exposição. [...] O que a CID mantém ainda como doença é o transtorno de identidade de gênero. Fico constrangido porque a psicóloga confundiu dois conceitos básicos, o de orientação sexual com o de identidade de gênero, que não necessariamente se confundem. Não é por que a CID ainda mantém o transtorno de identidade que alguém pode se valer disso para oferecer terapia de cura para a homossexualidade enquanto orientação sexual. [...] O psicólogo não deve reforçar essa egodistonia por meio de discursos que são no fundo religiosos. [...] Há uma violência simbólica do próprio Estado contra os homossexuais, na medida em que os exclui de direitos. E faz parte dessa violência simbólica o conjunto de discursos que demoniza, que desqualifica, que desumaniza os homossexuais, que não dá a eles a autonomia nem a liberdade de experimentar a sua orientação sexual com inteireza. É uma violência simbólica oferecer para a egodistonia um tratamento que reforce a egodistonia, um tratamento que na verdade mascara um proselitismo religioso. Porque, se formos observar, quase todos os argumentos utilizados para convencer a pessoa de que ela pode se curar são argumentos religiosos. Portanto há a ideia de que a homossexualidade é um pecado (CÂMARA DOS DEPUTADOS, 2012, n.p.).

A deputada pelo PT-DF, Érika Kokay (2012), apontou a parcialidade da mesa, considerando a ausência de representantes do movimento LGBT, e anunciou o requerimento de uma nova audiência pública, para discutir a ética profissional.

Nós estamos apresentando - o Deputado Jean Wyllys e eu - uma proposta de realização de audiência pública na qual possamos discutir a ética profissional. Porque essa postura do Conselho Federal de Psicologia é a mesma postura que existe no Conselho Federal de Serviço Social, é a mesma resolução que existe 
no Conselho Federal de Medicina, é a mesma resolução que existe na Ordem dos Advogados do Brasil (KOKAY, 2012, n.p.).

Dessa forma, em seis de novembro de 2012, foi realizada a segunda audiência, que teve como tema, o Exercício profissional do psicólogo, ética e respeito à homossexualidade. Presidida pela deputada Érika Kokay, teve os seguintes palestrantes: Toni Reis (representando a Associação Brasileira de Gays, Lésbicas, Bissexuais e Transgêneros - ABGLT); Ana Paula Uziel (representante do Conselho Nacional de Direitos Humanos do Conselho Federal de Psicologia, professora da Universidade Estadual do Rio de Janeiro (UERJ) e integrante do Centro LatinoAmericano em Sexualidade e Direitos Humanos - CLAM) e Francisco Cordeiro (consultor nacional da Organização Pan-Americana de Saúde no Brasil - OPAS).

Inicialmente, a deputada Érika Kokay (2012) assinalou que o PDC é baseado numa construção religiosa, inclusive colocando em risco o caráter laico do Estado, e, portanto, aquela audiência visava trazer reflexões à luz da ciência e da ética profissional. O representante da OPAS, Francisco Cordeiro, partindo do ponto de vista da saúde pública, defendeu que a diversidade é intrínseca à humanidade e o respeito às diferenças faz parte da convivência democrática, e que desconsiderar esta realidade pode potencializar o surgimento de instrumentos de controle social para grupos com características determinadas, induzindo ao desrespeito, intolerância, preconceito e estigma. Apresentou um documento da OPAS, que adverte que as supostas terapias de mudança de orientação sexual carecem de justificativas médicas e são eticamente inaceitáveis.

Toni Reis, representante da ABGLT, também fez referência ao documento da OPAS e levantou uma questão de fundo: a religiosidade no debate da cura gay. Adverte sobre o uso do sufixo ismo, que designa doença, o que justifica o uso do termo homossexualidade. Citou países que aplicam pena de morte, tais como Irã, Arábia Saudita, Sudão, Nigéria etc., para homossexuais e que tal medida é baseada nos livros sagrados. Toni Reis é especialista no tema da homofobia nas escolas, e destacou em sua fala, dados sobre o bullying homofóbico e suas consequências, sobretudo, a evasão escolar. Também apresentou dados oficiais sobre violência e discriminação contra pessoas LGBT. Mencionou ainda, as comunidades terapêuticas, que promovem a reversão da homossexualidade, com procedimentos aviltantes com seus usuários, como a exigência de se fazer exame de vírus da imunodeficiência humana (HIV), dentre outras violações, o que havia sido denunciado ao Ministério Público, que investigava o caso.

Por fim, palestrou Ana Paula Uziel, que disse que, como professora, estava preocupada com a formação do estudante de psicologia, haja vista o crescimento de alunos evangélicos na universidade. Apresentou informações sobre a regulamentação 


\section{A nova direita cristã: alianças, estratégias e transfiguração do discurso religioso em torno do projeto de cura gay}

da psicologia no Brasil e a criação dos conselhos federal e regionais, a fim de responder então, que o CFP tem autonomia para dar as diretrizes da prática ética no exercício da profissão, funcionando como um tribunal superior de ética profissional, e julga, em última instância os recursos das deliberações dos conselhos regionais. E esclareceu que, em geral, o sofrimento (relatado nos movimentos sociais, entre alunos ou nos consultórios) é decorrente de uma sociedade heterocêntrica, e que tal sofrimento deve ser acolhido pelo psicólogo. Sobre a resolução do CFP, que o PDC visa sustar, defendeu sua manutenção, pois ainda é necessária.

Nos debates, inscreveram-se os deputados Pastor Eurico do Partido Humanista da Solidariedade de Pernambuco (PHS-PE) e Marco Feliciano (PSC-SP), defensores do PDC, e seus questionamentos e posicionamentos tentaram desconstruir a relação feita entre o PDC e a homofobia, ao não se considerarem homofóbicos, tampouco que a homofobia seja intrínseca ao projeto.

Primeiro, eu gostaria de trazer à tona um questionamento que em todas as reuniões se fala: sobre a laicidade do Estado. Isso aqui não tem nada a ver com laicidade do Estado. [...] O que nos deixa perplexos é que os evangélicos neste Brasil, em todas essas discussões são tratados de homofóbicos. E homofobia é uma doença, é uma patologia clínica onde o homofóbico, ele não aceita as pessoas, não aceita as práticas, quer exterminar, destruir a pessoa, isso sim é homofobia. Nós evangélicos não andamos matando ninguém, principalmente homossexuais. Ao contrário, eu convivo com tantas pessoas homossexuais e nunca tive ódio ou quis matar; questão de princípios e um direito meu se eu não concordo com a prática homossexual, uma questão minha, que tem que ser respeitada também. [...] Agora, quando se trata da questão da psicologia, deixa a desejar alguns posicionamentos que foram tomados pelo CFP. [...] Se um homossexual busca o psicólogo, quer uma orientação, por que ele não pode ser atendido? Essa é a função do psicólogo. Mas aí, começou-se a marginalizar os profissionais da psicologia que tratam essas pessoas, que buscam a orientar. [...] Eu gostaria que nós pudéssemos pensar nos direitos, tanto se fala em direitos, é que os direitos dos homossexuais de hoje, que querem deixar o homossexualismo, eles possam também ser respeitados e os psicólogos possam lhes atender e orientá-los dentro daquilo que for possível (CÂMARA DOS DEPUTADOS, 2012, n.p.).

Na mesma linha de argumentação, se colocou o deputado Marco Feliciano:

Nós não lutamos contra seus direitos, inclusive eu falo sempre abertamente, embora eu tenha recebido o prêmio Pau de sebo, fui o terceiro mais votado pela comunidade LGBT (interessante que há dois piores do que eu), eu nunca pratiquei 


\section{Graziela Ferreira Quintão}

violência contra ninguém. A minha briga não é contra o movimento, a minha briga é contra os ativistas, porque os ativistas querem tudo, tudo e um pouco mais. Agora há pouco mesmo, a nossa deputada Érika Kokay, citou os negros e índios, os colocou no mesmo patamar dos gays. Negro nasce negro, ele não tem como mudar. Índio nasce índio, ele não tem como mudar, mas orientação sexual se muda. Eu conheço pessoas que eram gays, e que agora não são mais gays, são casadas e têm filhos. [...] Não queria que ninguém mais nos tachasse como homofóbicos, como obscurantistas, como caçador de bruxas, nem como fundamentalistas. Eu acho que o nosso diálogo tem que ser em nível intelectual, como está sendo aqui agora. [...] De repente, alguém tá pensado aqui: só tem dois pastores para discutir esse assunto, só esses dois que são contra tudo isso. $\mathrm{Na}$ verdade não, quando se fala do assunto homossexualidade aqui nesta casa; vai em off falar com cada um dos deputados, a maioria deles, $90 \%$ são tudo contra tudo que é feito aqui, mas quando você pede apoio a eles, eles dizem: não, não posso, porque a mídia vai vir para cima de mim, vão desconstruir a minha imagem, vou ser chamado de retrógrado, não vou ser progressista e coisas mais (CÂMARA DOS DEPUTADOS, 2012, n.p.).

Em 27 de novembro de 2012, foi realizada uma terceira audiência, onde se destaca a presença do pastor da Igreja Assembleia de Deus, Vitória em Cristo, Silas Malafaia, como defensor do PDC 234/11. Vale lembrar, que em 2004, tramitou na Assembleia Legislativa do Rio de Janeiro (ALERJ) um projeto que previa a alocação de recursos estatais para iniciativas religiosas voltadas à reversão da homossexualidade. O deputado estadual Samuel Malafaia, irmão de Silas, concedeu parecer favorável ao projeto, que acabou sendo rejeitado em plenária, em dezembro daquele ano, devido às reações de oposição de distintos atores sociais. (NATIVIDADE \& LOPES, 2009) As narrativas de defesa construídas por Silas Malafaia têm o sentido de legitimar o discurso religioso na arena política, a partir da apropriação (sem um rigor científico) de conhecimentos do campo da psicologia, psicanálise, genética etc., conforme alguns trechos de seu discurso:

A Psicologia não tem autoridade científica para dizer que alguém nasce ou não homossexual. Qual é o ramo da ciência que tem autoridade científica? A genética. A genética é o ramo da ciência que tem autoridade para dizer se alguém nasce ou não homossexual. Então, vamos lá. Não existe ordem cromossômica homossexual, não existem genes homossexuais, não existe libido homossexual do homem, macho ou fêmea. Um hormônio homossexual não existe, só há hormônio de macho e de fêmea. [...] Agora, quanto a Freud, que tanto vi na universidade e foi citado aqui, o pai da Psicanálise, será que os senhores esqueceram parte dos 


\section{A nova direita cristã: alianças, estratégias e transfiguraçâo do discurso religioso em torno do projeto de cura gay}

livros? Ele faz o estudo de uma mulher homossexual e chega à conclusão de que ela tinha uma questão com a figura paterna. Está nos escritos de Freud, senhores. Manda botar na fogueira da inquisição do Conselho Federal de Psicologia (CÂMARA DOS DEPUTADOS, 2012, n.p.).

Zylbersztajn (2012) não considera que a presença religiosa nos debates políticos seja algo antidemocrático em si, mas apenas evidencia a inexistência de recursos teóricos e argumentativos para a discussão do tema de forma qualificada. A este respeito, Rorty (1999) considera que o argumento puramente religioso precisa ser reestruturado e ganhar contornos seculares para ser apresentado na arena política. Partindo dessa premissa, analisamos que nos discursos dos defensores do PDC 234/11, ocorre uma transfiguração do discurso puramente religioso, com a apropriação de conhecimentos científicos de campos variados, a fim de legitimá-lo na arena política. Tal estratégia, contudo, torna seus argumentos bastante frágeis e consequentemente, facilmente desconstruídos, gerando muitas controvérsias e rejeição de vários setores da sociedade e oposição de atores sociais. O que levou o próprio autor do PDC, a requerer sua retirada de tramitação, em dois de julho de 2013. Na votação para o arquivamento, deputados de partidos mais à direita do espectro político parabenizaram a atitude do deputado João Campos, como o deputado do Piauí, Marcelo Castro (PMDB-PI):

O PMDB quer aproveitar a oportunidade para parabenizar o deputado João Campos, que, em boa hora, está retirando esse projeto. Isso é um retrocesso. Isso é de um obscurantismo, é de um atraso secular. Isso está pegando muito mal para o Congresso Nacional perante a opinião pública, nas manifestações populares (CÂMARA DOS DEPUTADOS, 2012, n.p.).

E também o deputado Mendonça Filho do Democratas (DEM-PE):

Acho que foi sábia a decisão do deputado João de propor a retirada do projeto. Ele gerou muita controvérsia, muita discussão e debates. Eu sou um liberal e, naturalmente, entendo claramente que a questão da sexualidade é uma disposição pessoal. Cada um tem a sua própria formação sexual, e não é esta Casa que vai ditar o caminho a ser seguido por quem quer que seja (CÂMARA DOS DEPUTADOS, 2012, n.p.).

Esse posicionamento dos deputados revela mais uma preocupação com as controvérsias públicas geradas pelo PDC, do que propriamente valores mais progressistas, afinal, estavam em curso à época, os movimentos de junho de 2013, 
com grande adesão da população em todas as regiões do país, que causou grande apreensão na classe política.

\section{Considerações finais}

O cenário político é constituído por diversos grupos sociais, com diferentes naturezas organizacionais de luta a favor de seus objetivos. Os interesses dos grupos podem ser definidos como o anseio de que, da política, seja extraída uma posição que favoreça determinado grupo ou segmento social. Na dinâmica relacional que se instaura nos processos de representação de interesses, há uma gama de atores envolvidos, como os atores governamentais (membros do Congresso, staff do Congresso, Presidente etc.), que são aqueles que recebem considerável atenção da imprensa e do público, tendo maior influência na definição da agenda governamental, atuando no fluxo dos problemas e política, e seu recurso mais decisivo é autoridade legal. Conforme vimos, os parlamentares evangélicos se utilizam de tais capitais e recursos, interferindo na agenda do movimento LGBT, com proposições que disputam a definição do que seja uma sexualidade legítima e de quais pessoas estão socialmente autorizadas a exercê-la, assim como conseguir o veto de leis e políticas públicas que contrariam preceitos morais da sua comunidade religiosa.

Conforme Machado \& Burity (2014), especialmente no discurso dos parlamentares, as posições conservadoras dos evangélicos em temáticas como direitos sexuais e combate à homofobia não devem ser necessariamente compreendidas como ataques à democracia. O que se pretende ressaltar contudo, é o fato de tais discursos e práticas, derivados de certas interpretações teológicas e exegeses bíblicas particulares, que deveriam se limitar aos templos religiosos, programas de rádio, televisão e outras mídias, adentrarem a arena política através dos parlamentares evangélicos que representam essas denominações religiosas, ferindo os princípios constitucionais da laicidade estatal. Zylbersztajn (2012) sustenta que a laicidade do Estado brasileiro não é plena, e que o processo de consolidação da laicidade é histórico e construído, tal como ocorre com os demais direitos fundamentais. De acordo com Pierucci (2009), pessoas livres (re)querem Estados laicos. O autor refere-se enfaticamente a mais secularização do Estado com seu ordenamento jurídico, e menos à secularização da vida, considerando que esta pode refluir, mas a do Estado não. 
A nova direita cristã: alianças, estratégias e transfiguração do discurso religioso em torno do projeto de cura gay

\title{
The new Christian right: alliances, strategies AND ALTERATIONS OF RELIGIOUS DISCOURSE surRounding Conversion Therapy
}

\begin{abstract}
The extension of $L G B T$ rights, as well as actions that promote the visibility and acceptance of these social groups have provoked conservative reactions from different aspects of the Christian faith, especially from Pentecostal evangelicals. The present article seeks to examine the role of congressmen of the Evangelical Parliamentary Front in the course of the draft constitutional decree (PDC $234 \backslash 2011)$, proposed by federal representative João Campos (PSDB-GO). It proposes an analysis focusing on the alliances, strategies and speeches developed in the political arena. As a methodological resource, reference is made to the speeches and debates delivered at public hearings for the above mentioned draft constitutional decree. As a source for consultation, we use the shorthand notes relating to the public hearings and ordinary meetings of the Federal Chamber of Human Rights and Minorities (CDHM) and the Social Security and Family Committee (CSSF), complemented by videos and materials circulated by the media that make reference to them.
\end{abstract}

KE YWORDS: Political-religious activism. Religious conservatism. PDC 234 । 2011. Evangelical Parliamentary Front. LGBT movement.

\section{REFERÊNCIAS}

BORRILLO, Daniel. Homofobia: história e crítica de um preconceito. Belo Horizonte: Autêntica Editora, 2013

CÂMARA DOS DEPUTADOS. Anais da ANC. 1993, n.p. Disponível em <http://www2. camara.leg.br/atividadelegislativa/legislacao/Constituicoes_Brasileiras/constituicao-cidada/ publicacoes/anais-da-assembleia-nacional-constituinte>. Acesso em 21 jan 2017.

Discursos e Notas Taquigráficas. 2012, n.p. Disponível em <http://www2.camara. leg.br/deputados/discursos-e-notas-taquigraficas>. Acesso em 18 jun. 2017.

CAMPOS, L. S. As origens norte-americanas do pentecostalismo brasileiro: observações sobre uma relação ainda pouco avaliada. REVISTA USP, SP, n.67, p. 100-115, set/nov 2005.

CONSELHO FEDERAL DE PSICOLOGIA (CFP). Resolução no 1 / 1999. Estabelece normas de atuação para os psicólogos em relação à questão da orientação sexual. Disponível em <http://site.cfp.org.br/resolucoes/resolucao-n-1-1999/>. Acesso em 18 jun. 2017. 
DUARTE, T. dos S. A Participação da Frente Parlamentar Evangélica no Legislativo Brasileiro: Ação Política e (In) vocação Religiosa. Ciencias Sociales y Religión, Porto Alegre,14, n.17, jul/dic 2012.

FOLHA DE SÃO PAULO. Pastor organiza abaixo-assinado para presidir comissão na Câmara. São Paulo, mar 2013, n.p. Disponível em: <http://www1.folha.uol.com.br/ poder/2013/03/1240319-pastor-organiza-abaixo-assinado-para-presidir-comissao-de-direitoshumanos.shtml>. Acesso em 20 mar 2014.

FRESTON, P. Protestantes e Política no Brasil: da Constituinte ao Impeachment. Tese de doutorado, IFCH/UNICAMP, Campinas, 1993.

HOWES, R. João Antônio Mascarenhas (1927-1998): pioneiro do ativismo homossexual no Brasil. Cad. AEL, v.10, n.18/19, 2003.

INSTITUTO BRASILEIRO DE GEOGRAFIA E ESTATÍSTICA - IBGE. Censo Demográfico 2010. Características Gerais da População, religião e pessoas com deficiência. Ministério do Orçamento, Planejamento e Gestão. Censo Demográfico, Rio de Janeiro, 2010. Disponível em: $<$ http://biblioteca.ibge.gov.br/pt/bibliotecacatalogo?view=detalhes\&id=794>. Acesso em 18 jun. 2017.

KOKAY, Érika. Discursos e Notas Taquigráficas. CÂMARA DOS DEPUTADOS DETAQ. Brasília/DF, 28 de junho de 2012, n.p. Disponível em: <http://www.camara.leg. $\mathrm{br} /$ internet $/ \mathrm{SitaqWeb} /$ TextoHTML.asp? etapa $=5 \&$ nuSessao $=181.2 .54$. O\&nuQuarto $=68 \& \mathrm{n}$ uOrador $=2 \&$ nuInsercao $=0 \&$ dtHorarioQuarto $=17: 21 \&$ sgFaseSessao $=$ CP\&Data $=28 / 06 / 201$ 2\&txApelido=ERIKA\%20KOKAY,\%20PT-DF>. Acesso em 18 jun. 2017.

MACHADO, M. D. C. \& BURITY, J. A Ascensão Política dos Pentecostais na Avaliação de Líderes Religiosos. Dados, vol.57, n.3, pp.601-631, 2014.

MARIANO, R. Expansão pentecostal no Brasil: o caso da Igreja Universal. Estudos Avançados, 18 (52), 2004.

NATIVIDADE, M. \& LOPES, P. V. L. O direito das pessoas GLBT e as respostas religiosas: da parceria civil à criminalização da homofobia. In DUARTE et al.(orgs). Valores Religiosos e Legislação no Brasil. Rio de Janeiro: Garamond, 2009.

PIERUCCI, A. F. Representantes de Deus em Brasília: A Bancada Evangélica na Constituinte. Ciências Sociais Hoje, ANPOCS/Vértice, p. 104-132, São Paulo, 1989.

. De olho na modernidade religiosa. Tempo Social: Revista de Sociologia da USP, v. 20, n. 2, p.9-16, 2008.

RORTY, R. Religion as a conversation stopper. In: . Philosophy and social hope.

Penguin Books, p. 168-174, 1999. 
A nova direita cristãa: alianças, estratégias e transfiguração do discurso religioso em torno do projeto de cura gay

ZYLBERSZTAJN, J. O Princípio da Laicidade na Constituição Federal de 1988. Tese de doutorado. Faculdade de Direito, USP, 2012.

Recebido em 11/02/2017.

Aprovado em 13/06/2017. 
